\title{
Reporting Adverse Drug Reactions Among Hospitalized Medical Patients: A Prospective Study From Tertiary Care Hospital in Western Nepal
}

\author{
Alam K¹, Shakya R 22, Ojha P3
}

${ }^{1}$ Assistant Professor of Pharmacology and Chief, Pharmaceutical Services, Manipal Teaching Hospital,

Pokhara, Nepal.

${ }^{2}$ Assistant Professor and Pharm D Program Coordinator, Department of Pharmacy, School of Science,

Kathmandu University, Dhulikhel, Kathmandu, Nepal.

${ }^{3}$ Department of Pharmacy, School of Science, Kathmandu University, Dhulikhel, Kathmandu, Nepal.

\section{Chief Editor}

\section{Dr. Subish Palaian}

\section{Technical Editor}

Mr. Shovit Khadka

Formatting Editor

Dr. Indrajit Banerjee
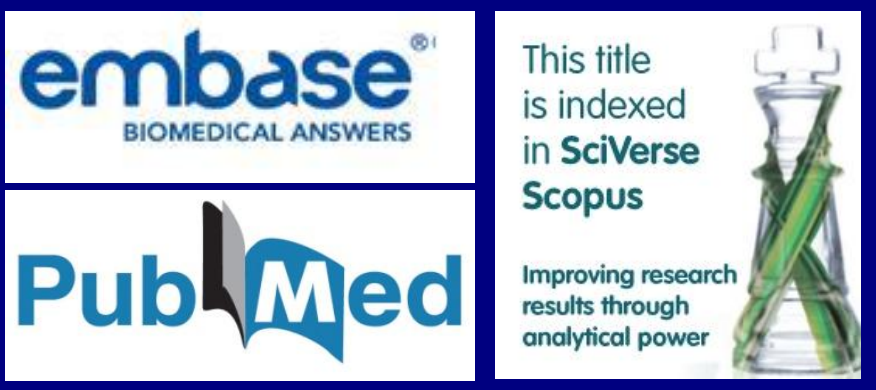

\section{Original Article}

\section{Corresponding Author}

Dr. Kadir Alam P.hD

Assistant Professor

Department of Pharmacology

Manipal College of Medical Sciences,

Pokhara, Nepal

Email: alamkad2050@yahoo.com

\section{Abstract}

\section{Background}

The risk of adverse drug reaction ranges nearly from zero to high level depending upon the drug itself and the patient factor. The process of detection, assessment, monitoring and reporting of adverse drug reaction is necessary to prevent its occurrence in future.

\section{Materials and Methods}

Information related to suspected Adverse Drug Reactions(ADRs) were collected by pharmacists from general medical ward using ADRs reporting form from Manipal Teaching Hospital (MTH)during ward rounds. The details of suspected drug, drug reaction and all related data were documented. Naranjo Algorithm, modified Hartwig and Siegel and modified Shumock and Thornton scale were used for assessment of causality, severity and preventability respectively. All suspected ADRs were reported to National Pharmacovigilance Center and then to Uppsala Monitoring centre through the electronic online data base named Vigiflow.

Results

Among 1,105 patients, 51 patients experienced ADR (4.61\%). Incidents of ADRs were higher with antibiotics (47.06\%) and Ceftriaxone was at top of list (15.69\%). 
Dermatological system (25.49\%) and gastrointestinal system (19.61\%) were affected more. About $33.33 \%$ of suspected drugs were discontinued. About $41.18 \%$ of ADRs required medical treatment where antihistaminic (24.32\%) and antipruritic (21.62\%) were most commonly used to treat ADRs. To sum up, $64.71 \%$ of ADRs were probable, $62.75 \%$ were mild in nature and $60.78 \%$ were probably preventable.

\section{Conclusion}

Finding of the study suggests that ADRs still pose serious health threat among hospitalized patients and as a matter of fact over $60 \%$ of them are preventable. Reporting of ADR scan provide effective measures to prevent the occurrence in the future in which the role of pharmacist is vital.

Keywords: Adverse Drug Reaction, Hospitalized patients, Reporting ADRs, Nepal.

\section{Introduction}

The issues of safety of drugs and reducing the risk factor of adverse drug reaction came into action only after the thalidomide disaster in 1961. Any drug which is used for its therapeutic effect can also produce adverse effects. The World Health Organization (WHO) defines an adverse drug reaction (ADR) as 'a response to a drug which is noxious and unintended, and which occurs at doses normally used in man for prophylaxis, diagnosis or therapy of disease, or for the modification of physiological function ${ }^{1}$.Adverse drug reaction is one of the categories of medication-related problems ${ }^{2}$. ADRs are a major cause of hospital admission and in-hospital morbidity ${ }^{3}$. ADRs among hospitalized patients can be divided into two broad categories: those that cause admission to hospital, and those that occur in inpatients after hospital admission. A study has shown that ADRs were responsible for $6.5 \%$ of all hospital admissions ${ }^{4}$. A meta-analysis indicated that ADRs were between the fourth to sixth commonest cause of death in the United States in 1994 and fatal adverse drug reactions were expected approximately $0.32 \%$ among hospitalized patients ${ }^{5}$. Nature of reaction, timing, relationship with dose and other possible causes are important factor to observe when an adverse drug reaction is suspected. The Naranjo Algorithm scale, modified Hartwig and Siegel scale and modified Shumock and Thornton scale are important tool to assess causality, severity and preventability respectively ${ }^{6-8}$. Most of the new medicines have been studied in a relatively small number of people in clinical trials before licensing. However, millions of patients may take these medicines. Since clinical trials are conducted under very strict conditions the rare reactions will only be seen and major reactions will be seen once the medicine is used in larger numbers of patients for long term. From 1975 to 2000, over $10 \%$ of the drugs approved by the USFDA either had to be withdrawn or achieved a "black box" warning because of unexpected adverse reactions ${ }^{9}$.

In Nepal, a new drug will be marketed only after the approval from the Department of Drug Administration
(DDA), the authorized body of the government of Nepal. The number of drugs available in the market is increasing day by day. The access to the information of such marketed drugs is very low. DDA acts as the national center for ADR monitoring under National Pharmacovigilance Program. In Nepal, pharmacovigilance activities were initiated in 2004. Currently there are seven regional centers and one national center in existence. Pharmacovigilance Center at Manipal Teaching Hospital is one among seven regional centers where present study was conducted. The concept of ADR monitoring in Nepal is still in preliminary stage ${ }^{10}$ as there is no mandatory law necessitating drug manufacturers to submit safety data from Nepalese population prior to approval of the medicines ${ }^{11}$. Even the health care professionals and consumers or patients are not much aware about it. A study from Nepal on attitude of healthcare profession about reporting of ADR found that $74.8 \%$ of healthcare professionals had seen patient experiencing an ADR. But, only $20.1 \%$ among them had reported $A D R^{12}$. Hence this study was carried out with following objectives:

- To study the incidence and pattern of ADRs in medical ward of a tertiary care hospital

- To assess the causality, severity and preventability of reported ADRs

- To find out drugs causing ADRs among patients of medical ward of a tertiary care hospital

- To study the management of ADRs among hospitalized patients

- To report the ADRs to National Pharmacovigilance Center through an online database VigiFlow

\section{Material and Methods}

\section{Study design and the participants}

A cross sectional survey was done for six Months (April 2012 to September 2012).

\section{Data collection}

The Study was carried out in general medical ward of Manipal Teaching Hospital (MTH). It is an 825 bedded tertiary care teaching hospital situated in Western Nepal. he patients admitted in unit I of General Medical Ward during study period were studied (General Medical Ward consists of unit I, unit II, semi ICU, COPD unit, psychiatric unit and skin unit). The researcher was involved in the ward round team with clinicians, nurses and other health care professionals. The ADRs detected and suspected drugs during ward round were noted in ADR Form. All the suspected cases of ADRs, drug involved and its management were discussed with the clinicians during ward. Informal interview was taken with patients and or patient's attendee where appropriate and treatments of ADR were recorded in Patient Profile Form. The documented ADRs were analyzed for causality, severity and preventability using Naranjo Algorithm scale, Modified Hartwig and Siegel scale and Modified Shumock and Thornton scale respectively. 


\section{Inclusion criteria}

Patients who stayed for at least 24 hours and used at least one medicine for their treatment were included in the study.

\section{Sample size calculation}

A Meta-analysis indicates that ADRs may occur in $16.88 \%$ of patients during hospitalization ${ }^{14}$. Using prevalence of this study, sample size can be calculated as follows

Where, $M=$ margin of error, $P=$ Prevalence of the characteristic

$$
n=\frac{Z_{\alpha / 2}^{2} \times P \times(1-P)}{E^{2}}
$$

Thus, the sample size $(n)$ at $95 \%$ confidence interval and $5 \%$ margin of error will be $\left[n=\left(1.96^{2} \times 0.17 \times 0.83\right) /(0.05)^{2}=\right.$ $216.81 \sim 217]$.

Although, the required sample size was only 217 , data collection was carried out for the duration of 4 months starting from April 2012 to July 2012 to obtain maximum sample size.

\section{Study Tools}

1. ADR reporting form: ADR reporting form was developed with slight modification of ADR reporting form of pharmacovigilance cell of MTH. This form included the details of patient demographic, ADRs and suspected drug.

2. Patient profile form: The patient profile form was developed by the researches which included the details of patient demographic, past medication and medical history, allergy, diagnosis, clinical laboratory values, medications used during admission, management of ADRs, and discharge medication.

3. Naranjo Algorithm scale ${ }^{6}$ : This scale was used to find the relationship between the drug and ADR. There are 10 questions related to drugs and ADRs. Naranjo scale categorize the ADR as Definite (score more than or equal to 9), Probable (5-8), Possible (1-4), Doubtful (Score less than or equal to 0$)$.

4. Modified Hartwig and Siegel scale ${ }^{7}$ : This scale was used to find the severity of ADRs. According to the scale, ADRs are categorized as mild (level 1 or level 2); moderate [level 3 or level $4(a)$ or level $4(b)$ ]; and severe (level 5 or level 6 or level 7).

5. Modified Shumock and Thornton scale ${ }^{8}$ : This scale was used for preventability assessment. Modified Shumock and Thornton scale categorized the preventability of ADR as definitely preventable, probably preventable and not preventable.

6. Vigiflow: This is web based program of the Uppsala monitoring center a WHO Collaborating center for reporting ADRs. This was used to report the ADRs to the Department of Drug Administration (DDA), the National Pharmacovigilance Center. The Vigiflow program requires following fields; report information, patient characteristics, results of tests and procedures, relevant medical history, relevant past drug therapy, reaction (s)/ event (s), list of suspected and concomitant drugs.

\section{Ethical committee approval}

Ethical approval for research was obtained from the institutional ethical committee of Manipal Teaching Hospital.

\section{Data management and statistical analysis}

SPSS Version 17 was used for data entry, recording and analysis. Descriptive statistics was used to present the data in the study.

\section{Results:}

\section{Demographic characteristics and Frequency of ADRs:}

A total of 1,105 patients were studied, among them 51 patients experienced ADR (4.61\%). Female patients (54.90\%) were slightly more exposed to ADRs than that of males. Geriatric patients (61 to 70 years of age) experienced more reactions $(23.53 \%)$. The detail of age and ADRs relationship is given in Figure 1.

Figure 1: Age of the patients experienced ADRs

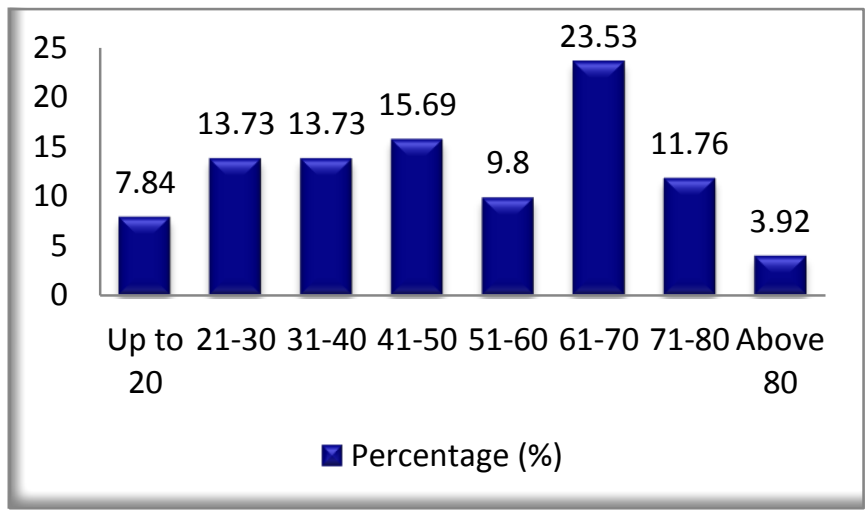

Category and route of administration of drugs causing ADRs: In the study 27 (52.94\%) ADRs were occurred after administration of oral drugs while 24 (47.06\%) cases occurred by parenteral drugs. Antibiotics were responsible for $47.06 \%$ of ADRs while cardiovascular drugs were responsible for $21.57 \% A D R s$. Anti-diabetic, benzodiazepine, analgesic, anticholinergic, anthelmintic, anti-rheumatic, diuretic, expectorants and iron supplement were responsible for remaining $31.36 \%$ of ADRs. Among cardiovascular drugs Amlodipine, Enalapril and Aspirin cause majority of ADRs. Ceftriaxone, combination of Amoxycillin and Clavulinic Acid, Ciprofloxacin and Ceftazidime caused more ADRs than other antibiotics. The top 10 drugs causing 30 out of 51 (58.82\%) ADRs are listed below in Table 1. 
Table 1: Top 10 drugs causing ADRs

\begin{tabular}{|c|c|c|c|}
\hline S. No. & Category & $\begin{array}{c}\text { Number } \\
\text { ADR }\end{array}$ & Percentage \\
\hline 1 & Ceftriaxone & 8 & 15.69 \\
\hline 2 & Amlodipine & 3 & 5.88 \\
\hline 3 & Amoxiclav & 3 & 5.88 \\
\hline 4 & Ciprofloxacin & 3 & 5.88 \\
\hline 5 & Enalapril & 3 & 5.88 \\
\hline 6 & Alprazolam & 2 & 3.92 \\
\hline 7 & Amitriptylline & 2 & 3.92 \\
\hline 8 & Aspirin & 2 & 3.92 \\
\hline 10 & Ceftazidime & 2 & 3.92 \\
\hline
\end{tabular}

Suspected ADRs and System affected by ADRs: Rashes (25.49\%), dizziness $(9.80 \%)$, hypotension(9.80\%), diarrhea (7.84\%), edema (7.84\%) were the main ADRs evident in the study. According to the system affected by suspected drugs, $25.49 \%$ of ADRs were dermatological followed by gastrointestinal (19.61\%), cardiovascular(17.65\%), central nervous systems (13.73\%)and others (endocrine and metabolic, respiratory, genitourinary, hematological and miscellaneous). The details of the system affected by the ADRs are given below in Figure 2.

Figure 2- System affected by ADRs

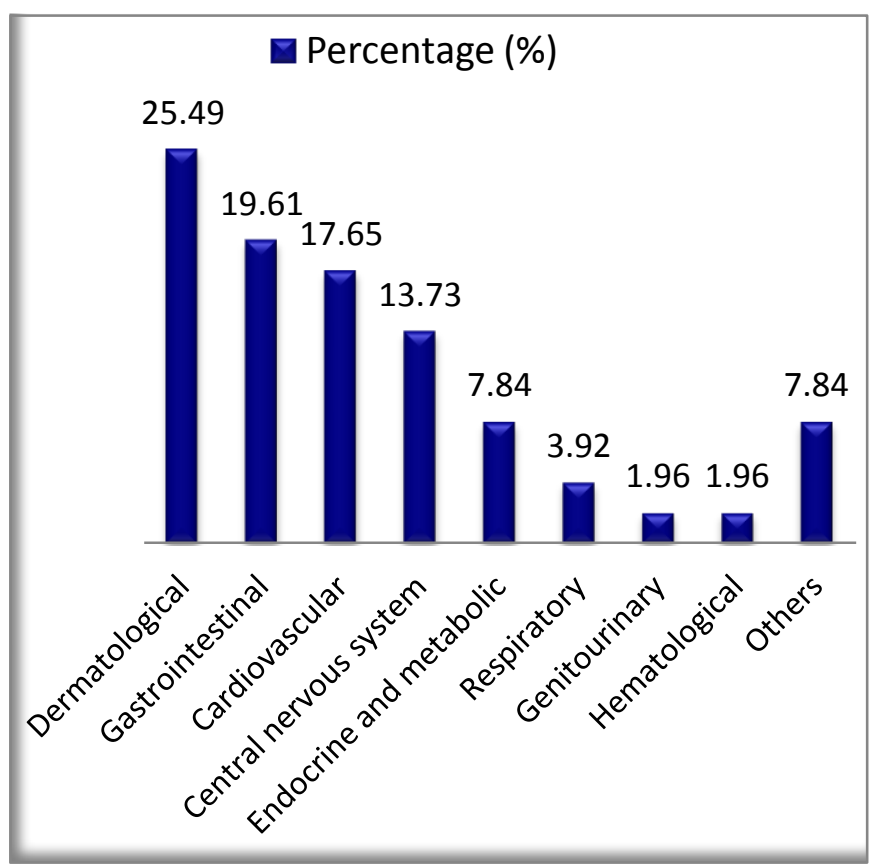

Assessment and Reporting of ADRs: The study concluded that $64.71 \%$ of ADRs probable, $43.14 \%$ of ADRs mild level 1 , and $17.65 \%$ of ADRs definitely preventable. The details of the assessment of ADRs are given in the Table 2.

All the ADRs found during the study were reported to the Department of Drug Administration (DDA), the national center, through regional pharmacovigilance cell at MTH using the online electronic data base program Vigiflow.

\section{Table 2- Assessment of ADRs}

\begin{tabular}{|c|c|c|c|}
\hline \multicolumn{2}{|c|}{ Assessment } & Number $(n=51)$ & \begin{tabular}{|c|} 
Percentage \\
$(100 \%)$
\end{tabular} \\
\hline \multirow{4}{*}{ Causality } & Definite & Nil & Nil \\
\hline & Probable & 33 & 64.71 \\
\hline & Possible & 18 & 35.29 \\
\hline & Doubtful & Nil & Nil \\
\hline \multirow{8}{*}{ Severity } & Mild Level -1 & 22 & 43.14 \\
\hline & Mild Level-2 & 10 & 19.61 \\
\hline & Moderate Level -3 & 15 & 29.41 \\
\hline & Moderate Level - 4(a) & 4 & 7.84 \\
\hline & Moderate Level - 4(b) & Nil & Nil \\
\hline & Severe Level -5 & Nil & Nil \\
\hline & Severe Level -6 & Nil & Nil \\
\hline & Severe Level -7 & Nil & Nil \\
\hline \multirow{3}{*}{ Preventability } & Definitely preventable & 9 & 17.65 \\
\hline & Probably preventable & 31 & 60.78 \\
\hline & Not preventable & 11 & 21.57 \\
\hline
\end{tabular}

Management and outcome of ADRs: In the study, only $19.61 \%$ of the suspected drugs were discontinued and $9.80 \%$ suspected drug doses were changed. Medical treatment was needed for 21 ADRs (41.18\%). Histamine antagonists were used among $24.32 \%$ of patients followed by antipruritic in $21.62 \%$, corticosteroids (16.22\%) and others. Details of drugs used for treatment of ADRs are given in Table 3.

Table 3- Drugs used to treat ADRs

\begin{tabular}{|c|c|c|c|}
\hline Drugs & No. of ADRs & $\begin{array}{c}\text { Percentage } \\
\text { (\%) }\end{array}$ & Type of ADRs \\
\hline $\begin{array}{r}\text { Calamine Lotion } \\
\text { oral }\end{array}$ & 8 & 21.62 & Dermatological \\
\hline $\begin{array}{r}\text { Hydrocortisone } \\
100 \text { mg IV }\end{array}$ & 5 & 18.92 & Dermatological \\
\hline $\begin{array}{r}\text { Pantoprazole } 40 \\
\text { mg Inj }\end{array}$ & 4 & 13.51 & $\begin{array}{c}\text { Cermatological, } \\
\text { Lactulose oral }\end{array}$ \\
\hline Paracetamol oral & 2 & 10.81 & Gastrointestinal \\
\hline Others & 2 & 5.41 & Gastrointestinal \\
\hline
\end{tabular}


In the study, $88.24 \%$ of ADRs were recovered while ADRs in $11.76 \%$ of patients were still continued even at the time of discharged.

\section{Discussion:}

\section{Demographic Characteristics and frequency of ADRs:}

This study revealed that among 1,105 patients, 51 (4.61\%) patients experienced ADRs which is similar to the figure of 3.5-7.5 \% of ADRs suggested in a systematic review ${ }^{13}$. A Meta-analysis indicates that ADRs may occur in $16.88 \%$ patients during hospitalization; however, this estimate has to be viewed with caution because there was significant heterogeneity ${ }^{14}$. Studies conducted on paediatric patients among hospitalized and tuberculosis patients found frequency of ADRs13.7 \% and $12.27 \%$ respectively ${ }^{15,16}$ which is about 3 times higher incidence than seen in this study. However, we could not find ADR incidence at similar setting to compare with our results. It was found that the number of female patients exposed to ADRs was slightly higher than male patients. An analysis of 48 cohort studies also reported that the percentage of female (20.6\%) exposed to ADRs was greater than male (12.9\%) patients and the age groups of 61 to 70 years were more in developing $A D R s^{17,18}$. The difference in hormonal and physiological system of female and male may be one of the reasons of experiencing more ADRs among female but the actual reason is not clear.

\section{Category and route of administration of drugs causing ADRs:}

This study showed that oral route is slightly more responsible than parenteral route of administration to cause ADRs. It was found that $52.94 \%$ of ADRs result due to oral route of drug while $47.06 \%$ was due to parenteral administration of drugs. In general practice, oral administration of drugs is considered to be safer than parenteral route of administration. But the present study showed that both group of drugs have similar potential to cause ADRs. The study showed antibiotics and cardiovascular drugs as major class of drugs causing ADRs and responsible for $47.06 \%$ and $21.57 \%$ respectively. Similar studies found that antibiotics, diuretics, cardiac glycosides, and anti diabetics as the drugs most frequently linked to ADRs ${ }^{18}$. Study conducted in Nepalese setting also reported antimicrobials, antihypertensives and analgesics most commonly causing ADRs ${ }^{10,11}$. Among cardiovascular drugs; Amlodipine, Enalapril and Aspirin cause ADRs more than others.

\section{Top 10 drugs causing ADRs:}

Among the top 10 listed drug, Ceftriazone was on the top level followed by Amlodipine, AmoxyClav, Ciprofloxacin, Enalapril and others. A study carried out in India reports that Cotrimoxazole, Ampicillin, Choloroquine, Ciprofloxacin were among the top 10 drugs causing $\mathrm{ADRs}^{19}$. But in this study, the result was different which may be due to the reason that Cotrimoxazole and Chloroquine were not frequently used in the setting where this present study was carried out. A study on antibiotic associated adverse events reported that Antibiotics were implicated in $19.3 \%$ of all emergency visits for drug-related adverse events and among them penicillins and cephalosporins were major drugs $^{20}$.

\section{Suspected ADRs and System affected by ADRs:}

During the study, the complaints of rashes, dizziness, hypotension, diarrhea, and edema were common ADRs whose occurrence was found $25.49 \%, 9.80 \%, 9.80 \%, 7.84 \%$, $7.84 \%$, respectively. Dermatological, gastrointestinal, cardiovascular, central nervous systems were mainly affected $(25.49 \%, 19.61 \%, 17.65 \%$ and $13.73 \%$ respectively) which is similar to studies conducted by Meena et al 2011, Sharma et al 2007 and Subish et al $2008^{19,21,22}$.

In the current study, since most of the cases were mild and moderate in nature, the suspected drug was continued among many cases by judging the benefit and risk ratio of the drug. In the study, $88.24 \%$ of ADRs were recovered among hospitalized patients but only $11.76 \%$ of them continued even at the time of discharge. The result of this study is similar to another study carried out in the same setting in which $87.5 \%$ patients recovered following the $\mathrm{ADR}^{16}$. In another prospective analysis of 18,820 patients, $97.71 \%$ of ADRs recovered ${ }^{4}$. This indicated that we can improve the condition of the patients and many of the reactions can be treated. But this needs monitoring, reporting and close observation of each steps of drug administration to the patient. Not a single patient died due to ADRs in our study. The detail of such data is still lacking in Nepal and as a result it is not possible to compare the result of the present study with similar research carried out previously.

\section{Assessment and Reporting of ADRs:}

The present study found that $64.71 \%$ of ADRs were probable and $35.29 \%$ were possible. The result was similar to one of the prospective analysis of 3695 patient episodes which had reported $66.5 \%$ of ADRs were probable and $30.4 \%$ possible $A D R s^{18}$. A study from one of the teaching hospital from Kathmandu, Nepal found $58.3 \%$ ADRs to be possible and $41.6 \%$ probable ${ }^{23}$. Moreover, the result of this present study was similar to one of the study carried out in India which had reported that $62.2 \%$ of ADRs were probable $^{24}$. Moreover, the causality result of our study was similar to the result of study done by Gonzalez et al in $1998^{15}$.

This research concluded that $43.14 \%$ of ADRs were mild level 1 , followed by $19.61 \%$ mild level $2,29.41 \%$ moderate level 3 and only $7.84 \%$ of moderate level $4($ a). A study from one of the teaching hospital from Kathmandu, Nepal found $47.2 \%$ were mild and $52.7 \%$ were moderate ${ }^{23}$. A study on prospective analysis of 3695 patient reported that $20.6 \%$ of cases were mild level 2 and $56.3 \%$ of cases were moderate level $3^{18}$. We did not found any severe ADRs in our study but a study conducted by Arulmani et al 2008 showed that $27.9 \%$ of ADRs were severe ${ }^{15}$. A study conducted in India reported that majority of the reactions $(53.7 \%)$ were mild ${ }^{24}$. The study concluded that $60.78 \%$ of ADRs were probable 
preventable, $17.65 \%$ definitely preventable and $21.57 \%$ not preventable. Our study indicates that near about $80 \%$ of ADRs are preventable. A study from one of the teaching hospitals from Kathmandu, Nepal found that 22.2\% ADRs were definitely preventable while $77.7 \%$ were not preventable $^{23}$. Poor coordination of care, lack of time and knowledge among health professionals, blame and shame system, complex pharmacokinetics and pharmacodynamics nature of drug and lack of patient education are some of the reason because of which we could not prevent the ADRs. One study reported that just over half of the ADRs were deemed possibly or definitely avoidable ${ }^{18}$.

\section{Management of ADRs:}

Management of ADRs is largely supportive and includes discontinuation of the offending medication, symptomatic treatment, and patient education ${ }^{25}$.Similarly in the study, around $20 \%$ of suspected drugs were discontinued. In this study most of reactions are related to dermatological and GIT system. Another study suggests first generation of antihistamines, mild topical steroids and moisturizing lotions are prime drugs in the management of acute cutaneous $\mathrm{ADRs}^{26}$. Similarly, in this study antihistaminic, calamine lotion and corticosteroids are commonly used medicines for management of ADRs.

\section{Conclusion:}

The study suggests that ADRs still pose serious problem among hospitalized patients. In this study, dermatological ADRs were more seen and higher incidence of ADR was noticed with Antibiotics and Drug Acting on Cardiovascular System. More than $60 \%$ of ADRs are preventable by the intervention of healthcare professionals. Assessment of causality, severity and preventability provides the link between drug therapy and ADRs. Reporting of ADRs can provide better way to prevent the future occurrence where pharmacist can play vital role.

\section{Future scope of study:}

Future studies are required to devise a standardized score for evaluation of SNS usage, and investigate the risks of excessive SNS use and addictive potential for providing appropriate education. While previous studies were regarding internet usage and addiction, the present study identified the subgroups of university students in the study area likely to overuse or be addicted to SNS. The results point to the need for further studies to establish these, overcoming the limitations of the present study.

\section{Acknowledgments}

The authors are thankful to all the physicians, nurses and the patients who were involved in the study. The authors also thank Prof. Dr. Panna Thapa, Dean, School of Science, Kathmandu University for his guidance and support. Our sincere thanks go to hospital management and ethical committee member of Manipal Teaching Hospital for their support and kind permission for research.

\section{Authors contributions}

All the authors KA, RS and PO were equally involved in designing this study. PO was more involved in data collection under supervision of first two authors. Author's contribution in preparing manuscript was according to their authorship given. All authors KA, RS and PO have gone through the manuscript and approved the same for publication.

\section{Conflict of Interests:}

The authors declare that they have no competing interests.

\section{References:}

1. Lee, A. \& Thomas, S.H.L. Adverse drug reactions In: Walker R and Edward C editors. Clinical pharmacy and Therapeutics. 3rd edition.Philadelphia: Churchill Livingstone; 2003.p. 33-46. PMCid:PMC200968

2. Hepler CD, Strand LM: Opportunities and responsibilities in pharmaceutical care. Am J Hosp Pharm. 1990; 47:53343.

\section{PMid:2316538}

3. Wu TY, Jen MH, Bottle A, Molokhia M, Aylin P, Bell D, et al: Ten-year trends in hospital admissions for adverse drug reactions in England 1999-2009. J R Soc Med2010;103:23950.

http://dx.doi.org/10.1258/jrsm.2010.100113

PMid:20513902 PMCid:PMC2878823

4. Pirmohamed M, James S, Meakin S, Green C, Scott AK, Walley TJ,et al.: Adverse drug reaction as cause of admission to hospital: prospective analysis of 18820 patients. BMJ 2004; 329: 15-19. http://dx.doi.org/10.1136/bmj.329.7456.15 http://dx.doi.org/10.1136/bmj.329.7463.460-a PMid:15231615 PMCid:PMC443443

5. Lazarou J, Pomeranz B, Corey PN: Incidence of adverse drug reactions in hospitalized patients. $A$ meta-analysis of prospective studies. JAMA 1998; 279: 1200-5. http://dx.doi.org/10.1001/jama.279.15.1200 PMid:9555760

6. Naranjo CA, Busto U, Sellers EM, Sandor P, Ruiz I, Roberts $E A$, et al: A method for estimating the probability of adverse drug reactions. Clin Pharmacol Ther 1981; 30(2): 239-45.

http://dx.doi.org/10.1038/clpt.1981.154

7. Hartwig SC., Siegel J, Schneider PJ: Preventability and severity assessment in reporting Adverse Drug Reactions. Am J Hosp Pharm. 1992; 49:2229-32. PMid:1524068

8. Lau PM, Stewart K, Dooley MJ: Comment: hospital admissions resulting from preventable adverse drug reactions. Ann Pharmacother 2003; 37: 303-5. http://dx.doi.org/10.1345/aph.1A333a

9. Lasser KE, Allen PD, Woolhandler SJ, Himmelstein DU, Wolfe SM, Bor DH: Timing of new black box warnings and 
withdrawals for prescription medications. J Am Med Assoc2002; 287: 2215-20. http://dx.doi.org/10.1001/jama.287.17.2215 PMid:11980521

10. Subish P, Ibrahim MIM, Mishra P: Pattern of adverse drug reactions reported by the community pharmacists in Nepal. Pharmacy Practice (Internet) 2010;8(3): 201-7.

11. Jha N, ShankarPR, BajracharyaO, GurungSB, SinghKK: Adverse drug reaction reporting in a pharmacovigilance centre of Nepal. Australas Med J. 2012; 5(5): 268-71 http://dx.doi.org/10.4066/AMJ.2012.1142

PMid:22848322 PMCid:PMC3395286

12. Santosh KC, Tragulpiankit P, Gorsanan S, EdwardsIR: Attitudes among healthcare professionals to the reporting of adverse drug reactions in Nepal. BMC Pharmacol Toxico. 2013; 14: 16.

http://dx.doi.org/10.1186/2050-6511-14-16

PMid:23497690 PMCid:PMC3599543

13. Wiffen P, Gill M, Edwards J, Moore A: Adverse drug reactions in hospital patients. A systematic review of the prospective and retrospective studies. Bandolier Extra 2002;1-16.

14. Miguel A, Azevedo LF, Araujo M, Pereira AC: Frequency of adverse drug reactions in hospitalized patients: a systematic review and meta-analysis. Pharmacoepidemiol Drug Saf. 2012;21(11):1139-54.

http://dx.doi.org/10.1002/pds.3309

PMid:22761169

15. Gonzalez-Martin G, Caroca CM, Paris E: Adverse drug reactions (ADRs) in hospitalized pediatric patients. A prospective study.Int J Clin Pharmacol Ther. 1998; 36(10):530-3.

PMid:9799056

16. PV K, Palaian S, Ojha P, P RS: Pattern of adverse drug reaction experienced by tuberculosis patients in a tertiary care teaching hospital in Western Nepal. Pak. J. Pharm. Sci.2008; 21(1): 51-6. 17 Martin RM, Biswas PN, Freemantle SN, Pearce GL, Mann RD: Age and sex distribution of suspected adverse drug reactions to newly marketed drugs in general practice in England: analysis of 48 cohort studies. Br J Clin Pharmacol.1998; 46(5): 505-11. PMid:9833605 PMCid:PMC1873702

18. Davies EC, Green CF, Taylor S, Williamson PR, Mottram DR, Primohamed M: Adverse Drug Reactions in Hospital InPatients: A Prospective Analysis of 3695 Patient-Episodes. PLoS ONE 2009; 4(2): e4439. http://dx.doi.org/10.1371/journal.pone.0004439

PMid:19209224 PMCid:PMC2635959

19. Shrivastava M, Uchit G, Chakravarti A, Joshi G,Mahatme M, Chaudhari H: Adverse Drug Reactions Reported in Indira Gandhi Government Medical College and Hospital, Nagpur. JAPI 2011; 59.

20. Shehab N, Patel PR, Srinivasan A, Budnitz DS: Emergency department visits for antibiotic-associated adverse events. Clin Infect Dis. 2008 Sep 15;47(6):735-43 http://dx.doi.org/10.1086/591126 PMid:18694344

21. Sharma H, Aqil M, Imam F, Alam MS, Kapur P, Pillai KK: A pharmacovigilance study in the department of medicine of a university teaching hospital. Pharmacy Practice 2007; 5(1): 46-9.

22. Subish $P$, Mishra $P$, Shankar PR: Systemic adverse drug reactions: A preliminary report from the regional pharmacovigilance center, Western Nepal. Pak. J. Pharm. Sci. 2008. 21 (4): 465-7

23. Jha N, Bajracharya O, Shrestha R, Thapa HS, Shankar PR: Starting a pharmacovigilance program within a teaching hospital: challenges and experiences from Lalitpur, Nepal. Southern Med Review 2009; 1:7-10

24. Arulmani R, Rajendran SD, Suresh B: Adverse drug reaction monitoring in a secondary care hospital in South India. $\mathrm{Br} J$ Clin Pharmacol 2008;65(2):210-6. http://dx.doi.org/10.1111/j.1365-2125.2007.02993.x PMid:17662089 PMCid:PMC2291214

25. Riedl MA, Casillas AM. Adverse drug reactions:types and treatment options. Am Fam Physician 2003; 68 (9): 1781-90.

PMid:14620598

26. Nayak S, Acharjya B. Adverse cutaneous drug reaction. Indian J Dermatol 2008; 53 (1): 2-8. http://dx.doi.org/10.4103/0019-5154.39732 PMid:19967009 PMCid:PMC2784579

\begin{tabular}{|l|l|}
\hline \multicolumn{2}{|c|}{ Article Information } \\
\hline \multicolumn{2}{|c|}{ Article history } \\
\hline Received & $3^{\text {rd }}$ February 2014 \\
Received in revised form & $25^{\text {th }}$ March 2014 \\
Accepted & $26^{\text {th }}$ March 2014 \\
\hline
\end{tabular}

